\title{
BMJ Open Comparing cognitive-behavioural psychotherapy and psychoeducation for non-specific symptoms associated with indoor air: a randomised control trial protocol
}

Sanna Selinheimo, ${ }^{1}$ Aki Vuokko, ${ }^{1}$ Markku Sainio, ${ }^{1}$ Kirsi Karvala, ${ }^{1}$ Hille Suojalehto, ${ }^{1}$ Heli Järnefelt, ${ }^{1}$ Tiina Paunio ${ }^{1,2}$

To cite: Selinheimo S, Vuokko A, Sainio M, et al. Comparing cognitivebehavioural psychotherapy and psychoeducation for non-specific symptoms associated with indoor air: a randomised control trial protocol. BMJ Open 2016;6: e011003. doi:10.1136/ bmjopen-2015-011003

- Prepublication history for this paper is available online. To view these files please visit the journal online (http://dx.doi.org/10.1136/ bmjopen-2015-011003).

SS and AV contributed equally.

Received 29 December 2015 Accepted 11 May 2016

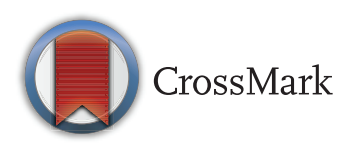

${ }^{1}$ Finnish Institute of Occupational Health, Helsinki, Finland

${ }^{2}$ Department of Psychiatry, University of Helsinki, Helsinki, Finland

Correspondence to Sanna Selinheimo; sanna.selinheimo@ttl.fi

\section{ABSTRACT}

Introduction: Indoor air-related conditions share similarities with other conditions that are characterised by medically unexplained symptoms (MUS)-a combination of non-specific symptoms that cannot be fully explained by structural bodily pathology. In cases of indoor air-related conditions, these symptoms are not fully explained by either medical conditions or the immunological-toxicological effects of environmental factors. The condition may be disabling, including a non-adaptive health behaviour. In this multifaceted phenomenon, psychosocial factors influence the experienced symptoms. Currently, there is no evidence of clinical management of symptoms, which are associated with the indoor environment and cannot be resolved by removing the triggering environmental factors. The aim of this study is to compare the effect of treatment-as-usual (TAU) and two psychosocial interventions on the quality of life, and the work ability of employees with non-specific indoor air-related symptomatology.

Methods and analyses: The aim of this ongoing randomised controlled trial is to recruit 60 participants, in collaboration with 5 occupational health service units. The main inclusion criterion is the presence of indoor air-related recurrent symptoms in $\geq 2$ organ systems, which have no pathophysiological explanation. After baseline clinical investigations, participants are randomised into interventions, which all include TAU: cognitive-behavioural psychotherapy, psychoeducation and TAU (control condition). Health-related quality of life, measured using the $15 \mathrm{D}$-scale, is the primary outcome. Secondary outcomes include somatic and psychiatric symptoms, occupational factors, and related underlying mechanisms (ie, cognitive functioning). Questionnaires are completed at baseline, at 3, 6 and 12-month followups. Data collection will continue until 2017. The study will provide new information on the individual factors related to indoor air-associated symptoms, and on ways in which to support work ability.

Ethics and dissemination: The Coordinating Ethics Committee of the Hospital District of Helsinki and

\section{Strengths and limitations of this study}

- Evidence-based treatments that may effectively reduce indoor air-associated medically unexplained or functional symptoms, and support the health-related quality of life are urgently needed.

- We use manualised treatments for the condition.

- The study protocol is carried out with occupational health services through multicentre collaboration.

- Difficulties in the recruitment process may challenge the implementation of the study.

- The length of the follow-up may lead to participant drop out.

Uusimaa, Finland, has granted approval for the study. The results will be published in peer-reviewed journals. Trial registration number: NCT02069002; Preresults.

\section{INTRODUCTION}

Medically unexplained or functional symptoms (MUS) consist of a combination of symptoms without pathophysiology. ${ }^{1-4}$ These non-specific symptoms may occur concurrently with similar disease symptoms and in various organ systems, including respiratory systems. ${ }^{5} 6$

A combination of indoor air-associated symptoms, including respiratory, mucosal and skin, as well as general symptoms, are common in non-industrial work environments. ${ }^{7}$ In some patients, symptoms persist despite building up remediation or removal of the factors that provoke indoor air symptoms; ${ }^{8-13}$ these are not explained by either asthma or other medical conditions, and thus remain medically unexplained. ${ }^{8} \quad 13$ 
In addition to MUS, non-specific chronic symptoms associated with indoor air overlap with the idiopathic environment intolerance (IEI) proposed by the International Programme on Chemical Safety (IPCS). ${ }^{14}$ IEI is defined as multiple, recurrent symptoms associated with various environmental factors that are generally tolerated at low levels, as well as with significant lifestyle or functional impairments related to these symptoms. ${ }^{14-16}$ Both functional symptomatologies and IEI may lead to considerable disability and diminish the quality of life. ${ }^{17}$

Psychological factors such as cognitive functioning, perceptions of health outcomes, and emotional issues are associated with poorer physical health outcomes ${ }^{18}$ and combine with MUS and IEI. Illness perceptions and worry, for example, have been shown to lead to higher symptom reports in chronic diseases, such as asthma, ${ }^{5} 19$ in concordance with MUS ${ }^{20-22}$ and IEI. ${ }^{23}{ }^{24}$ Challenging these dysfunctional illness perceptions may improve health outcomes. ${ }^{18}$ As in the treatment of chronic medical disorders, such as asthma, individual factors related to health behaviour ${ }^{25}$ must be taken into account in indoor air-related symptomatology.

Moreover, in MUS, predisposing factors (ie, negative affectivity and early life experiences) and perpetuating factors (ie, cognitive processes including external or a monocausal attributional styles, illness worry and rumination, illness behaviour and emotional distress) are related to symptom maintenance. ${ }^{26-28}$ These factors interact with prolonged physiological activation to produce symptoms of chronic stress. ${ }^{29}$ The findings also support the hypothesis that worry and perseverative cognition are related to the enhanced activity of physiological markers that act directly on somatic symptoms, including pain, coughing and breathing difficulties. ${ }^{30}$ The vicious circle of cognitive, behavioural, physical and emotional factors has been shown to predict MUS. ${ }^{22}$

Indoor air-associated symptoms are influenced by physical, psychosocial and personal factors, often through multiple mechanisms. ${ }^{31} 32$ Thus, the management of symptoms associated with indoor air requires a multifactorial approach (figure 1). In randomised controlled trials of MUS, cognitive-behavioural interventions, including patient education, activity regulation strategies and illness attribution replacement from monocausal or catastrophising to more adaptive strategies, have shown to be effective for patients suffering from MUS. ${ }^{27}{ }^{33-36}$ The goal of cognitive-behavioural psychotherapy $(\mathrm{CBT})$ is to identify factors that maintain

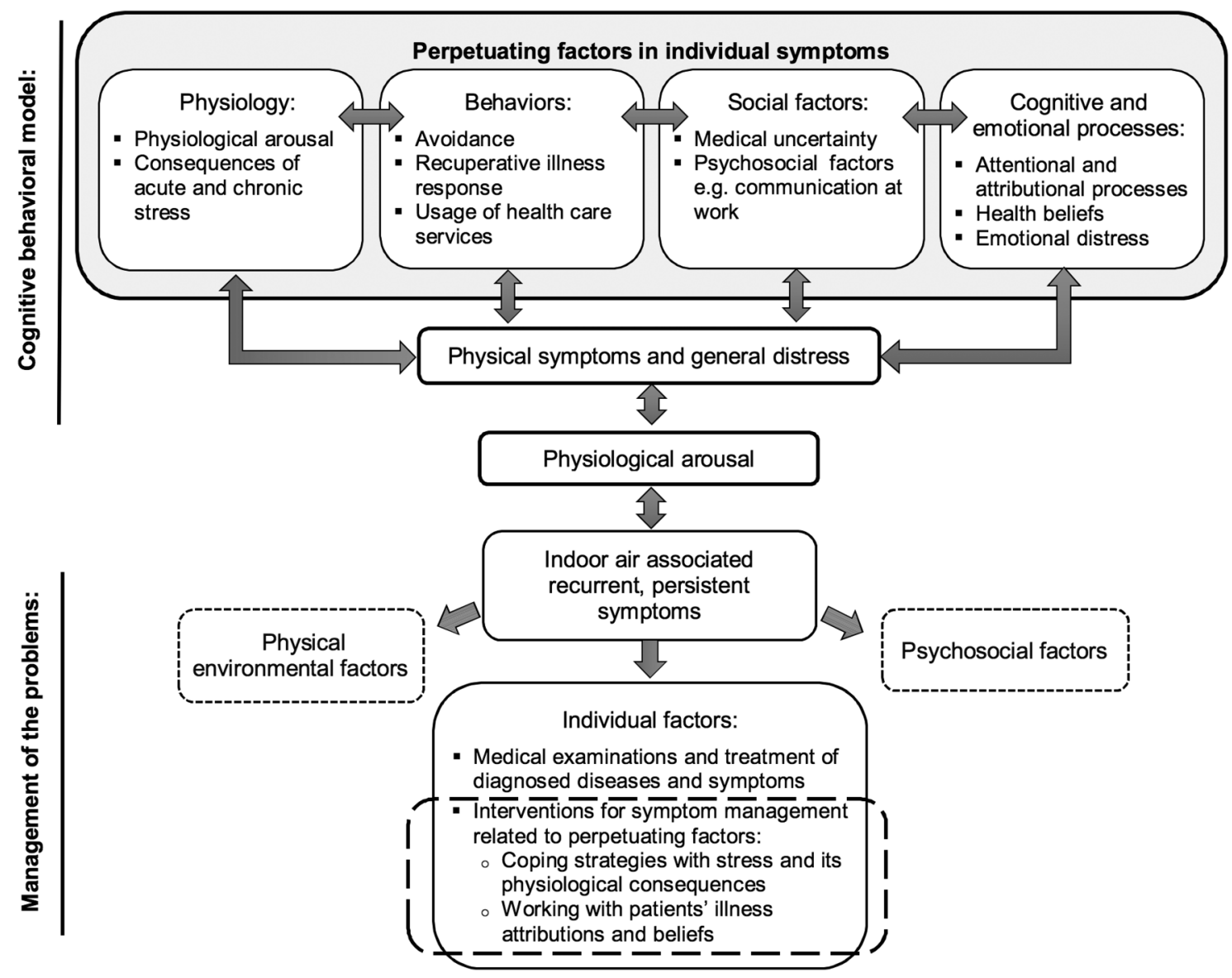

Figure 1 Cognitive-behavioural model of hypothesised cycle of symptom perpetuation (extended after Deary et $a^{27}$ ) and the focus of the present RCT study (encircled). The focus is part of a multifactorial approach to managing symptoms associated with indoor air. RCT, randomised controlled trial. 
symptomatology, and support adaptive attributional styles and patient strengths so that quality of life is mediated via better health behaviour and symptom regulation. In addition, a relaxation technique called applied relaxation $(\mathrm{AR})^{37}$ has shown to be effective in reducing physiological arousal related to stress through relaxation and support of stress management. ${ }^{38}$ So far, information regarding effective treatment options for indoor air-associated persistent symptomatologies is scarce. ${ }^{13} 39$

In this study, we hypothesise that non-specific symptoms associated with indoor air share features with MUS, and could be treated according to similar principles. In our previous study, tertiary care patients with symptoms associated with indoor air that had features of MUS did not respond to limited counselling. ${ }^{13}$ A plausible explanation might have been the long symptom history, which requires more intensive interventions. The aim of the present clinical trial is to investigate the effectiveness of two psychosocial treatments in comparison to treatment-as-usual (TAU) for persistent indoor airassociated symptoms among occupational primary healthcare patients. The primary outcome is improved quality of life. The secondary aim is to investigate whether the treatments decrease patients' overall symptoms and improve work ability, and to identify the psychological factors that affect the patients' responses to the treatment.

\section{METHODS}

\section{Study population}

The participants of this study are recruited from occupational health service (OHS) units and their eligibility is assessed by an occupational physician (OP) and an occupational health nurse (OHN). The participants must have recurrent multiorgan symptoms that are attributed to workplace indoor air, including respiratory symptoms and disability with no medical explanation. For symptom definition we use the IEI criteria (table 1) according to which the obvious medical diseases and exposure-related factors that could explain the symptoms, and affect the outcome of the intervention are excluded from OHS before enrolment (table 1. Exclusion criteria). Patients enrolled at the Finnish Institute of Occupational Health (FIOH) undergo an additional clinical evaluation of respiratory symptoms to distinguish asthma symptoms from functional respiratory symptoms.

\section{Study design}

This study is an ongoing randomised controlled superiority trial (RCT) of three parallel groups. The original

\section{Table 1 Inclusion and exclusion criteria of study}

\begin{tabular}{|c|c|}
\hline Criteria & Description \\
\hline \multicolumn{2}{|l|}{ Inclusion } \\
\hline Age and gender & Age $25-58$ years, female and male \\
\hline \multirow{3}{*}{$\begin{array}{l}\text { Symptom } \\
\text { definition* }^{*}\end{array}$} & (A) Self-reported symptoms attributed to indoor work environment (non-industrial workplaces) include \\
\hline & $\begin{array}{l}\text { (B) Symptoms recurrently (1) occur in more than one indoor environment, or (2) continue despite } \\
\text { measures at the workplace to solve the indoor air problem (eg, work arrangements and/or workplace } \\
\text { reparations), and }\end{array}$ \\
\hline & $\begin{array}{l}\text { (C) Symptoms are not adequately explained by medical reasons (symptoms are medically } \\
\text { unexplained) } \dagger\end{array}$ \\
\hline Symptom duration & Onset of recurrent symptoms with disability of $\leq 3$ years before the study \\
\hline Work & Employed for $\geq 3$ years before the study \\
\hline Sick leave & At least 1 day of sick leave due to indoor air symptoms during the preceding 6 months \\
\hline Language & Fluent Finnish (writing/reading/speaking) \\
\hline \multicolumn{2}{|l|}{ Exclusion } \\
\hline $\begin{array}{l}\text { Sick leave } \\
\text { duration }\end{array}$ & $\begin{array}{l}\geq 6 \text { months of sick leave due to indoor air symptoms during the preceding } 2 \text { years and currently unable } \\
\text { to work }\end{array}$ \\
\hline Changes in work & Changes in work (eg, retirement, study leave, pregnancy, etc.) during the study \\
\hline \multirow[t]{5}{*}{ Medical reasons $†$} & Some serious and/or acute untreated medical disease or illnesses: \\
\hline & $\begin{array}{l}\text { A. Somatic disease that explains the symptoms (eg, uncontrolled asthma, and/or disease causing } \\
\text { disability) }\end{array}$ \\
\hline & $\begin{array}{l}\text { B. Psychiatric disorder (depression, moderate or severe; bipolar disorder; psychotic disorders; } \\
\text { obsessive-compulsive disorders; eating disorders; and/or severe personality disorders) }\end{array}$ \\
\hline & C. Alcohol and/or drug dependency or abuse \\
\hline & D. Developmental disorders \\
\hline Psychotherapy & Psychotherapy (current or ended during two preceding years) \\
\hline Other & Patient refusal; not actively participating in work life (retired or unemployed) \\
\hline
\end{tabular}

${ }^{*}$ IEI-criteria modified from Lacour et al. ${ }^{15}$

†Based on evaluation of occupational physician. Other criteria may also be evaluated by occupational health nurse.

IEI, idiopathic environment intolerance. 
study plan included four arms: individual CBT, psychoeducation, TAU and group 'administered' AR. The arm (AR) requiring group formation was excluded from the protocol due to difficulties in the recruitment process (figure 2). The study is carried out by FIOH in collaboration with five large OHS units, including three public and two private enterprises in the district of Helsinki and Uusimaa, Finland. The inclusion and exclusion criteria were piloted in OHS A before enrolment. The participant flow, data collection and intervention programme timeline is outlined in figure 2.

Before enrolling participants for the intervention, the OPs and OHNs participate in a 1-1.5-hour training session led by the researchers (AV, SS). Each recruiter receives a personal recruitment manual including the following: a description of the study procedure, inclusion/exclusion criteria, patient information, informed consent, questionnaire on indoor air factors and arrangements at the workplace and prepaid envelopes for returning the enrolment documents. The manual also contains a non-identifiable inquiry to collect the reasons for refusing to participate in the study despite meeting inclusion criteria. Information letters (eg, in OHS unit and on the intranet) are available for the use of OHS to inform employees and employers of ongoing study collaboration. The researchers are regularly in contact with the recruiters during enrolment in order to maintain the recruitment.

Before informed consent, participant candidates receive oral and written information on the study from

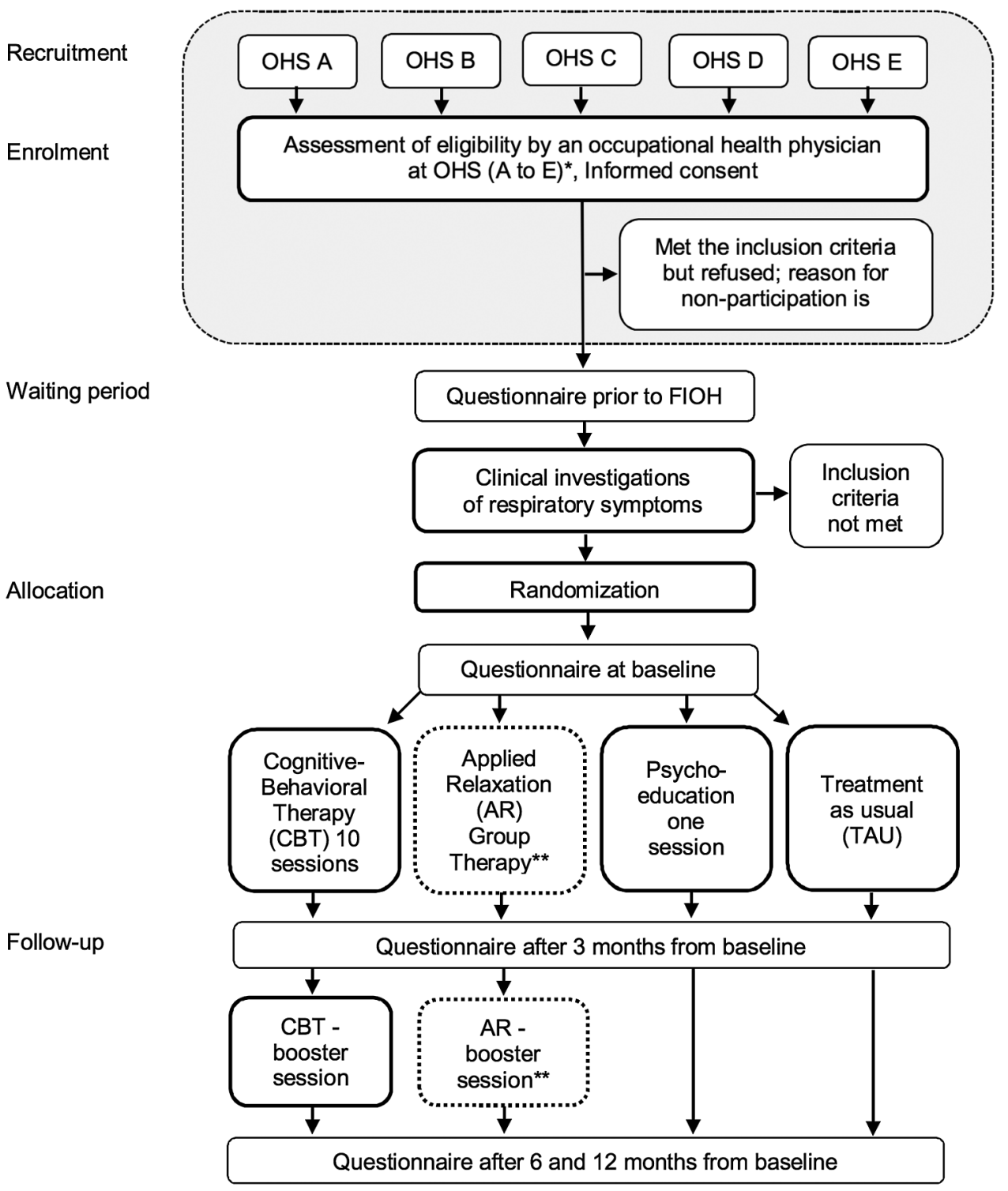

Figure 2 Flow chart of study. ${ }^{*} \mathrm{OHS}$ (A to E) join the study consecutively: (A and B) in January 2014, (C) in June 2014, (D) in August 2014, and (E) in March 2015. Participant recruitment began: (A and B) in 24th February 2014, (C) in July 2014, (D) in September 2014 and (E) in May 2015. ${ }^{*} A R$ Group Therapy discontinued during study due to slow, prolonged recruitment process. FIOH, Finnish Institute of Occupational Health; OHS, occupational health service. 
their OHS specialists. All recruited participants prefill a questionnaire and attend a medical evaluation of respiratory symptoms at $\mathrm{FIOH}$, which includes a 2-week diurnal measurement of peak expiratory flow and bronchial hyperresponsiveness. ${ }^{40}$ 41 A respiratory physician (HS) evaluates the results, and each participant receives a report. In cases of uncontrolled asthma or if other exclusion criteria are revealed, the participant is excluded.

Before the participants are recruited, they are allocated into the three arms of the study by preprogrammed randomisation into numerical listing. The groups are stratified to contain participants from different OHS units, workplaces and genders with an allocation ratio of 1:1:1. After the clinical investigations, investigators (SS and AV) allocate eligible participants into either intervention conditions or the control (TAU) conditions that are next in order in listing after stratification. Each group contains 20 individuals. The first author contacts participants by telephone and email to inform them of their allocation after randomisation. During the study, all participants receive TAU based on individual needs from their OHS. Participants are asked for permission to use their medical records for evaluating TAU during the study. They reply to web-based questionnaires through a secure internet connection at baseline, and then at follow-up at 3,6 and 12 months. The confidentiality of the participants is protected by using an encryption key for personal details in the data.

The participants are recruited during the period from February 2014 to autumn 2016 (the closing date will be decided in early autumn 2016 after recruitment status is updated, and this will be sometime at the end of 2016). The aim was to recruit 80 participants in total. During the first 6 months, seven eligible participants were recruited who constituted $30 \%$ of the 6-month aim. During the next 6 months, 11 eligible participants were recruited. After 1 year of recruitment, the low number of participants $(\mathrm{N}=18)$ showed that it was difficult to find eligible individuals. Therefore, so as not to overextend the waiting period and logistics of the interventions, the AR group therapy arm of the study was discontinued, and participants were randomised into the two individual interventions and TAU. In May 2015, after agreement with the study steering group (April 2015), and approval from Ethics Committee's for the change in the study plan, the AR arm was removed from study interventions to ensure completion of the study. Thus, the number of recruited participants decreased to a total of 60 . The follow-up results are expected 12 months after the last recruited participant enters the study (approximately, in the spring of 2017), and the preliminary results are expected during 2017.

\section{Intervention}

The intervention programmes were developed at FIOH on the basis of previously studied intervention protocols for multiple similar symptomatology conditions. ${ }^{13} 3334363842$ All interventions are described in detail in the intervention manuals (in Finnish). Depending on the participants' approval, all CBT and psychoeducation sessions are recorded for post hoc reliability, and checked to ensure intervention integrity so that the intervention is implemented as intended. ${ }^{43}$

\section{Individual CBT}

CBT consists of 10 manualised sessions. The first $90 \mathrm{~min}$ introduction is followed by nine $45 \mathrm{~min}$ individual sessions at weekly intervals, and the last two sessions at 2-week intervals. One booster session will be conducted 3 months after treatment ends. The sessions include information on stress-related exacerbation of indoor airassociated symptoms and personal health behaviour factors integrated into the patients' own symptomatology; cognitive restructuring behavioural training for patients' health-promoting behaviour at home between the sessions; imagery rescripting; and relapse prevention (table 2). CBT sessions are delivered by three psychologists licensed to be psychotherapists. The psychologists

Table 2 Summary of contents of CBT sessions

\section{Sessions Contents}

1 Treatment overview and description of treatment as intervention focusing on behavioural training and monitoring. Situation analysis, patient's symptoms and establishing rapport. Setting of personal goals for the intervention and filling of first part of symptom-emotion-cognition-monitoring form.

2-3 Discussion on how stress affects patients' health and physiological consequences of stress. Coping strategies for stress and stress decreasing activities. Working with illness worries and symptom-perception interaction.

4-5 Personal strengths and the vicious circle of symptom behaviour. Patient's dysfunctional health and indoor air related beliefs, for example, catastrophising and cognitive restructuring.

6-7 Evaluation of goals, discussion of obstacles that interfere with achieving them. Validation of frustration and support of meaningful activities. Patient stress-reducing techniques and work-related activities.

8-9 Health-related information and discussion on how to react to contradictory information regarding health-related issues. Increased awareness of emotions and how these affect symptom perception.

10 Identifying warning signs that may affect recurrence of symptoms and working with patients to plan future actions if symptoms recur.

11 Follow-up and booster session 3 months after intervention.

$\mathrm{CBT}$, cognitive-behavioural psychotherapy. 
had clinical experience of 6-13 years, during which they had undergone 4 years of psychotherapy training (cognitive, cognitive-behavioural and integrative psychotherapy), and had worked as psychotherapists for $0.5-7$ years before the study. To ensure treatment integrity, ${ }^{43}$ the psychotherapists attended training sessions before the treatment and were supervised during the treatment. Training was arranged by the researchers (AV, SS), and detailed intervention materials, which specified the content of each session (eg, dosage), were provided.

\section{Individual psychoeducation intervention}

This is one manualised 90 min individual session delivered by a psychologist (SS) and a specialist in occupational medicine (AV). The intervention includes (1) an overview of the main indoor exposures, (2) general information on the symptoms and health risks associated with the indoor environment, and (3) information regarding factors that affect individual health behaviour and symptom management (table 3 ).

\section{AR group therapy}

The original study plan included an arm with AR group therapy delivered by two psychologists. This consisted of seven manualised face-to-face sessions: one $120 \mathrm{~min}$ group session followed by six $90 \mathrm{~min}$ sessions, as described earlier. ${ }^{374}$ The sessions were planned to be delivered at weekly intervals, the last two sessions at 2-week intervals, and a booster session 3 months after the treatment ended. The intervention was intended to include behavioural training focusing on AR techniques, and a discussion of $\mathrm{AR}$ as a coping strategy that can be used in cases of acute symptoms, and for symptom and relapse prevention. As described earlier, AR was later removed from the protocol due to difficulties in the recruitment process.

\section{Ethics, data protection and dissemination}

The interventions are blind to the data collected and the characteristics of individuals. The confidentiality of

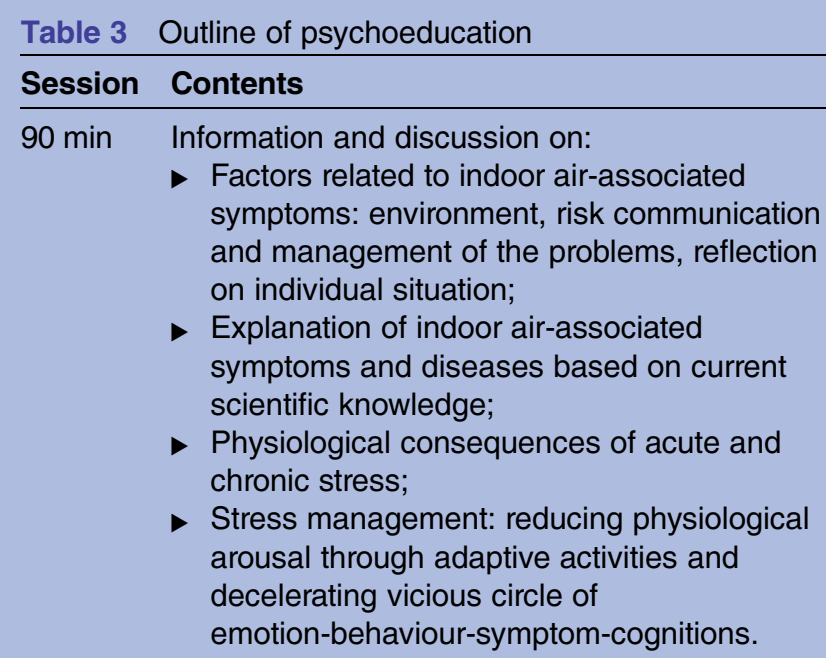

- Explanation of indoor air-associated symptoms and diseases based on current scientific knowledge;

- Physiological consequences of acute and chronic stress;

- Stress management: reducing physiological arousal through adaptive activities and decelerating vicious circle of emotion-behaviour-symptom-cognitions.

the participants is protected by an encryption key to personal data. The key is stored separately. All data are treated and implemented according to national data security laws. The results will be published in a peerreviewed journal and presented at conferences.

\section{Outcome measures}

The study is designed to evaluate the effectiveness of different psychosocial interventions for the health-related quality of life, measured using the $15 \mathrm{D}$ scale as the primary outcome. ${ }^{45} \quad 46$ The $15 \mathrm{D}$ is a generic, 15-dimensional standardised measure composed of physical, mental and social well-being. The dimensions include mobility, vision, hearing, breathing, sleeping, eating, speech, elimination, usual activities, mental function, discomfort and symptoms, depression, distress, vitality and sexual activity. Each dimension has five grades of severity ( $1=$ the highest/best level; $5=$ the lowest/worst level). In this study, the $15 \mathrm{D}$ is used as a single sum score measure with values from 1 (full health) to 0 (dead) as a primary outcome, but a profile can also be presented as descriptive data. In addition, we also measure secondary outcomes such as work ability and job strain, cognitive and emotional functioning and psychiatric symptoms (table 4). Background information, such as medical history and work ability, is also collected. The description and chronology of the assessments are shown in table 4 .

\section{Sample size}

Sample size was calculated in order to detect a clinically significant difference between the treatment arms in primary outcome measure $15 \mathrm{D}$, the single index score ranging from 0 (dead) to 1 (full health). As a measure of clinical significance, we used a SD of 0.03 , as based on a nationally representative standardisation of the $15 \mathrm{D}$ scale. ${ }^{75}$ According to the power analyses, an estimate of the required sample size is $\mathrm{N}=20$ eligible participants per group. It was assumed that $\sim 30 \%$ (one of three) recruited patients would not meet the inclusion criteria when examined at FIOH. It is further assumed that the follow-up attrition will be $\leq 20 \%$. Thus, to achieve a significance level of 0.05 when requiring $80 \%$ power, a sample size of $\mathrm{N}=17$ participants per group is needed to find a clinically significant difference of $\mathrm{SD}=0.03$ in $15 \mathrm{D}$ between the arms.

\section{Plan of statistical methods}

Before the analyses, the group allocation (TAU, psychoeducation or CBT) will be concealed at FIOH by a researcher who is not involved in the trial. Summary statistics (frequencies, means and SD) of baseline and follow-up data will be analysed and reported. The level of significance will be set at $p<0.05$. Categorical outcomes will be analysed using the $\chi^{2}$ test or Fisher's exact test. When appropriate, we will use the t-test and the Mann-Whitney $\mathrm{U}$ test to compare the baseline and follow-up outcomes of 
Table 4 Assessments and their time schedule

\begin{tabular}{|c|c|c|c|c|c|c|}
\hline \multirow[b]{2}{*}{ Assessment and evaluation method } & \multicolumn{6}{|c|}{ Time of measurement (months) } \\
\hline & & $<0$ & BL & 3 & 6 & 12 \\
\hline \multicolumn{7}{|l|}{ Primary outcome } \\
\hline $15 \mathrm{D}$ instrument ${ }^{* 4546}$ & Q & & $\mathrm{X}$ & $\mathrm{X}$ & $\mathrm{X}$ & $\mathrm{X}$ \\
\hline \multicolumn{7}{|l|}{ Secondary outcomes } \\
\hline \multicolumn{7}{|l|}{ Occupational functioning } \\
\hline Self-assessed work ability ${ }^{47}$ & Q & $\mathrm{X}$ & & $\mathrm{X}$ & $\mathrm{X}$ & $\mathrm{X}$ \\
\hline Job strain 4849 & Q & $\mathrm{X}$ & & & & $\mathrm{X}$ \\
\hline Need for Recovery (NRF) $)^{50}$ & Q & & $\mathrm{X}$ & $\mathrm{X}$ & $X$ & $\mathrm{X}$ \\
\hline \multicolumn{7}{|l|}{ Psychiatric symptoms } \\
\hline Generalised Anxiety Disorder 7 (GAD-7) ${ }^{\star 51}$ & Q & & $\mathrm{X}$ & $\mathrm{X}$ & $\mathrm{X}$ & $\mathrm{X}$ \\
\hline Insomnia Severity Index (ISI) ${ }^{\star 52}$, In Finnish ${ }^{53}$ & Q & & $\mathrm{X}$ & $\mathrm{X}$ & $\mathrm{X}$ & $\mathrm{X}$ \\
\hline The Symptom Checklist-90 (SCL-90) ${ }^{\star 54} 55$ In Finnish ${ }^{56}$ & Q & & $\mathrm{X}$ & $\mathrm{X}$ & $\mathrm{X}$ & $\mathrm{X}$ \\
\hline The Patient Health Questionnaire (PHQ-9) ${ }^{57}$; In Finnish ${ }^{58}$ & Q & & $X$ & $\mathrm{X}$ & $\mathrm{X}$ & $\mathrm{X}$ \\
\hline \multicolumn{7}{|l|}{ Cognitive and emotional functioning } \\
\hline $\begin{array}{l}\text { The Acceptance and Action Questionnaire-II (AAQ-II) }{ }^{5960} \\
\text { in Finnish. Tuomisto M. } 2007 \text { and } 2011\end{array}$ & Q & & $\mathrm{x}$ & $\mathrm{X}$ & $\mathrm{X}$ & $\mathrm{X}$ \\
\hline IIIness Worry Scale (IWS) 6162 & Q & & $\mathrm{X}$ & $\mathrm{X}$ & $\mathrm{X}$ & $\mathrm{X}$ \\
\hline Penn State Worry Questionnaire (PSWQ) ${ }^{63}$ in Finnish, Tuomisto M. 2002 & Q & & $\mathrm{X}$ & $\mathrm{X}$ & $\mathrm{X}$ & $\mathrm{X}$ \\
\hline Strategy and Attribution Questionnaire (SAQ) ${ }^{\star 64}$ & Q & & $\mathrm{X}$ & & $\mathrm{X}$ & $\mathrm{X}$ \\
\hline \multicolumn{7}{|l|}{ Assessment of treatment alliance and satisfaction } \\
\hline Working Alliance Inventory $(\mathrm{WAI}) \dagger^{65} 66$ & Q & & & & & \\
\hline Treatment satisfaction $\ddagger^{67}$ & Q & & & $\mathrm{X}$ & $\mathrm{X}$ & $\mathrm{X}$ \\
\hline \multicolumn{7}{|l|}{ Background variables } \\
\hline Demographics (age, gender, marital status, education) & Q & $\mathrm{X}$ & & & & \\
\hline \multicolumn{7}{|l|}{ Clinical characteristics } \\
\hline Health, diagnosed diseases and medication & Q & $X$ & & & & $\mathrm{X}$ \\
\hline Alcohol Use Disorders Identification Test (Audit) ${ }^{\star 68}$ & Q & $\mathrm{X}$ & & & & $\mathrm{X}$ \\
\hline Asthma Control Test $(\mathrm{ACT}) \S^{69}$ & Q & $\mathrm{X}$ & & & & $\mathrm{X}$ \\
\hline General symptoms & Q & $\mathrm{X}$ & $\mathrm{X}$ & $\mathrm{X}$ & $\mathrm{X}$ & $X$ \\
\hline Peak Expiratory Flow (PEF)-measurements for 2 weeks ${ }^{41}$ & $\mathrm{~L}$ & $X$ & & & & \\
\hline Bronchial hyper-responsiveness ${ }^{40}$ & $\mathrm{~L}$ & $\mathrm{X}$ & & & & \\
\hline The Quick Environmental Exposure and Sensitivity Inventory (QEESI) ${ }^{70}$ & Q & $\mathrm{X}$ & & & & $\mathrm{X}$ \\
\hline Home environment & Q & $\mathrm{X}$ & & & & $x$ \\
\hline Work characteristics and occupational functioning & Q & $X$ & & & & $\mathrm{x}$ \\
\hline The Holmes and Rahe stress scale ${ }^{71}$ & Q & $X$ & & & $\mathrm{X}$ & $\mathrm{X}$ \\
\hline \multicolumn{7}{|l|}{ Personality and social functioning functions } \\
\hline Short Five (S5) personality inventory ${ }^{\star 72}$ & Q & $\mathrm{X}$ & & & & \\
\hline The Inventory of Interpersonal Problems (IIP) ${ }^{73}$ & Q & $\mathrm{X}$ & & & & $x$ \\
\hline Sense of Coherence (SOC-13) ${ }^{\star 74}$ & Q & $\mathrm{X}$ & & & & $\mathrm{x}$ \\
\hline
\end{tabular}

*Psychometric properties of the Finnish population are good.

†n the Cognitive Behaviour Therapy arm, the participants and the psychotherapists fill the Working Alliance Inventory (WAI) after first, fifth and last (10th) session.

fln the psychoeducation arm, the participants answer the 5-question Treatment Satisfaction questionnaire.

$\S$ The Finnish version of the ACT. The ACT is a trademark of Quality Metric Incorporated 2002 GlaxoSmithKline.

$\mathrm{BL}$, baseline; L, medical investigation; $\mathrm{Q}$, questionnaire.

the groups. Analysis of variance or covariance will be used for multiple comparisons of the groups, and for examining changes in the groups. Item-level missing or error values due to coding are not expected because of the computerised forced protocol for the questionnaire. We will use both analysis of study completers and an intent-to-treat-analysis, meaning that each missing value is replaced by the last observed value of that questionnaire to handle drop-out data. Post hoc analysis will be used to evaluate the individual factors related to the effectiveness of the interventions, and additional per protocol analysis will also be conducted. Statistical analyses will use the latest version of IBM-SPSS for Windows (SPSS Illinois, Chicago, Illinois, USA) software.

\section{DISCUSSION}

This study examines the efficacy of psychosocial interventions among primary patients with OHS who have symptoms associated with indoor air in multiple organ systems and a disability with no medical explanation. In addition, the study aims to identify the psychological factors that affect the patients' response to the treatment. The focus is to decrease the non-specific 
symptoms and disability associated with the indoor environment. Our previous study among tertiary care patients with long-lasting symptoms and disability showed that psychosocial factors also ${ }^{32}$ have a substantial influence on the symptoms experienced in indoor environments. ${ }^{13}$ This RCT is conducted to provide evidence of the benefit of early intervention for OHS patients. To the best of our knowledge, there are no previous studies in similar settings.

The strength of this study is that the participants are recruited from OHS, which is part of Finland's overall primary healthcare and covers almost $90 \%$ of the working population. ${ }^{76}$ OHS focuses on preventing workrelated diseases, and promotes health and work ability through measures at workplaces. For a great deal of employees, OHS also provides general healthcare and treatment. This enables us to evaluate the usefulness of the psychosocial interventions in the OHS context. In this study, the participants are clinically investigated by the recruiting OPs, and the additional clinical examination at FIOH ensures that there is no medical condition behind the patient's symptomatology and disability. Detailed data of the measures taken at the workplace and the participants' health status are also recorded. The longitudinal follow-up design increases the strength of the evaluation's effectiveness.

The possible health effects of physical, biological and chemical factors in the indoor environment have been extensively studied but, so far, the role of toxicological mechanisms in the real life human exposure situations for these problems has remained ambiguous. ${ }^{24} 77$ Along with these indoor environmental factors, it is crucial to understand the patients' illnesses and recovery processes. Compared to the standard treatment for chronic diseases, such as asthma, the results provide evidence of the potential benefit of psychosocial management programmes that measure, for example, asthma-specific quality of life and reduced asthma severity scores. ${ }^{78} 79$ Our focus is on individual factors related to the recovery process and outcome.

Certain study limitations deserve attention. Occupational and organisational changes may have an impact on motivation to participate and stay in the study. Possible changes in OHS systems (eg, if the employer changes OHS provider during the study) may also affect the recruiting process. In addition, selection bias may exist if those who volunteer to participate are, for example, more interested in psychosocial treatment than the non-participating employees. Some data show that patients' expectations may affect treatment outcomes. ${ }^{80}$ On the other hand, 10 CBT sessions, including homework and practising, requires longer commitment to treatment than limited psychoeducation. This might increase the drop-out rate in the CBT group. Moreover, during the waiting period, participants are contacted, clinically examined and randomised; this may have a placebo effect on a patient's condition. This in turn may weaken intervention effects.
In spite of the public concern regarding building related health problems, until now, the study recruitment has been unexpectedly slow. Challenges in recruitment processes indicate that cultural models and the population's attitudes to indoor air-related symptoms need to be evaluated. In biomedical healthcare settings, underestimation of the psychosocial dimensions of the distress associated with somatic syndromes and a patient's fear of stigmatisation may lead to under-treatment of the illness. ${ }^{82}$ Moreover, patients with MUS and IEI typically provide monocausal or definitive attribution to environmental or biological factors. ${ }^{20} 28$ However, taking only one perspective of these multifaceted phenomena in MUS and IEI cases would diminish effective treatment options, and thus challenge the present study which focuses on improving stress reduction and health behaviour. These societal factors might bias the study population. The participants are chosen using well-defined inclusion and exclusion criteria in order to diminish heterogeneity among the study participants, and to avoid evident confounding factors that may affect the trial. In this study, we compare psychosocial interventions to standard treatment and we can estimate the individual factors related to the effectiveness of the interventions in post hoc analysis within the treatment groups. We cannot, however, examine the effectiveness of the interventions themselves or, for example, determine which aspects (special contents, intervention length, etc) explain the possible differences between the groups.

Our randomised controlled trial will provide new information on the possible beneficial effects of psychosocial interventions on non-specific symptoms associated with indoor air. The results will hopefully improve evidence-based practices that intervene in indoor airassociated symptomatologies.

\section{TRIAL STATUS}

This study has been registered at the ClinicalTrials.gov registry (NCT02069002). Patient enrolment began on 24 February 2014, and is planned to continue until approximately the end of 2016 (based on the steering group's decision taken on 6 April 2016). Results from the study are expected in 2017.

\section{ETHICS AND DISSEMINATION}

The Coordinating Ethics Committee of the Hospital District of Helsinki and Uusimaa, Finland, has granted approval for this study (number 107/13/03/00/13). The study is registered and data is handled in accordance with the Personal Data Act (523/1999). FIOH is the data controller.

The results will be published in peer-reviewed journals. All results will be reported without any identifiable personal information. Participation in the study will have no effect on the participants' healthcare. Neither OHS nor the participant's employer will receive any information on study participation, or any personal study results. 
No side effects or serious risks are expected from participation in psychoeducation or cognitive behavioural psychotherapy. However, if any should occur during the treatment, the participants will be offered individual counselling from the medical person in charge of the study, and be referred for relevant treatment elsewhere, if considered appropriate.

\section{STUDY MONITORING}

The research trial procedures will be audited by the steering group every 6 months. The steering group monitors and evaluates data management and if necessary, requests changes to the protocol. If the protocol is modified, the approval of the ethics committee is requested, and the ClinicalTrials.cov registry is informed. All authors will be given access to the cleaned data sets. A separate datamonitoring committee was not considered necessary as the risks to participants were expected to be minimal.

Acknowledgements The authors would like to warmly acknowledge the Steering group of the project: Kirsi Vainiemi (Medical Advisor, the Social Insurance Institution of Finland, Research Department), Anne-Marie Kurka (PhD, The Finnish Work Environment Fund), Päivi Metsäniemi (Chief physician, medical development, Terveystalo healthcare service company), Mika Mäkelä (Professor, Chief Physician, Skin and Allergy Hospital, Helsinki University Hospital and University of Helsinki, Finland), Sirkku Saarikoski (PhD, Adjunct Professor, Ministerial Advisor, Ministry of Social Affairs and Health, Department of Occupational Safety and Health), Eira Viikari-Juntura (Research Professor, Finnish Institute of Occupational Health). The authors are also grateful to psychotherapists Susanna Juselius, Riitta Suvanto-Witikka, and Carita Alanne, and the study nurses for their contribution.

Collaborators Collaboration was with the following occupational health service units: The Occupational Health Centre of the city of Espoo, Terveystalo healthcare service company (Finland), Mehiläinen Oy healthcare service company (Finland), The Occupational Health Centre of the city of Vantaa, The Occupational Health Centre of the city of Helsinki.

Contributors TP conceived the study idea and finalised the research plan in collaboration with SS, AV, MS, KK, HJ, HS and Christer Hublin. SS provided statistical expertise. SS and AV participated in the recruitment of the OHS. SS and $A V$ are responsible for the management and co-ordination of the study, and questionnaire data collection. SS wrote the first version of the manuscript with AV. TP, MS, KK, HS, and HJ helped in drafting of the manuscript. All authors provided feedback on the drafts, and read and approved the final manuscript. TP is the guarantor of the study.

Funding The Finnish Work Environment Fund (ref 113076) and the Social Insurance Institution of Finland (KELA) (ref 23/26/2014). Neither the authors' institutions nor the funders have any authority over trial activities or preparing of the manuscript.

\section{Competing interests None declared.}

Patient consent Obtained.

Ethics approval The Coordinating Ethics Committee of Hospital District of Helsinki and Uusimaa, Finland approved the trial study protocol and its change in May 2015 (107/13/03/00/13).

Provenance and peer review Not commissioned; externally peer reviewed.

Open Access This is an Open Access article distributed in accordance with the Creative Commons Attribution Non Commercial (CC BY-NC 4.0) license, which permits others to distribute, remix, adapt, build upon this work noncommercially, and license their derivative works on different terms, provided the original work is properly cited and the use is non-commercial. See: http:// creativecommons.org/licenses/by-nc/4.0/

\section{REFERENCES}

1. Burton $C$. Beyond somatisation: a review of the understanding and treatment of medically unexplained physical symptoms (MUPS). $\mathrm{Br} \mathrm{J}$ Gen Pract 2003;53:231-9.

2. Wessely S, Nimnuan C, Sharpe M. Functional somatic syndromes: one or many? Lancet 1999;354:936-9.

3. Rosendal M, Fink P, Falkoe E, et al. Improving the classification of medically unexplained symptoms in primary care. Eur $J$ Psychiatry 2007;21:25-36.

4. Fink P, Schröder A. One single diagnosis, bodily distress syndrome, succeeded to capture 10 diagnostic categories of functional somatic syndromes and somatoform disorders. J Psychosom Res 2010;68:415-26.

5. Lehrer P, Feldman J, Giardino N, et al. Psychological aspects of asthma. J Consult Clin Psychol 2002;70:691-711.

6. Crook B, Burton NC. Indoor moulds, sick building syndrome and building related illness. Fungal Biol Rev 2010;24:106-13.

7. WHO. Indoor air pollutants: exposure and health effects. EURO reports and studies 78. Copenhagen: WHO Regional Office for Europe, 1983.

8. Al-Ahmad M, Manno M, Ng V, et al. Symptoms after mould exposure including Stachybotrys chartarum, and comparison with darkroom disease. Allergy 2010;65:245-55.

9. Edvardsson B, Stenberg B, Bergdahl J, et al. Medical and social prognoses of non-specific building-related symptoms (Sick Building Syndrome): a follow-up study of patients previously referred to hospital. Int Arch Occup Environ Health 2008;81:805-12.

10. Haverinen-Shaughnessy U, Hyvärinen A, Putus T, et al. Monitoring success of remediation: seven case studies of moisture and mold damaged buildings. Sci Total Environ 2008;399:19-27.

11. Iossifova YY, Cox-Ganser JM, Park JH, et al. Lack of respiratory improvement following remediation of a water-damaged office building. Am J Ind Med 2011;54:269-77.

12. Sauni R, Verbeek JH, Uitti J, et al. Remediating buildings damaged by dampness and mould for preventing or reducing respiratory tract symptoms, infections and asthma. Cochrane Database Syst Rev 2015;2:CD007897.

13. Vuokko A, Selinheimo S, Sainio M, et al. Decreased work ability associated to indoor air problems - an intervention (RCT) to promote health behavior. Neurotoxicology 2015;49:59-67.

14. IPCS (International Programme on Chemical Safety). Report of multiple chemical sensitivities (MCS). http://apps.who.int/iris/ bitstream/10665/63109/1/PCS_96.29.pdf (accessed Dec 2015).

15. Lacour M, Zunder T, Schmidtke K, et al. Multiple chemical sensitivity syndrome (MCS)-suggestions for an extension of the US MCS-case definition. Int J Hyg Environ Health 2005;208:141-51.

16. Das-Munshi J, Rubin GJ, Wessely S. Multiple chemical sensitivities: review. Curr Opin Otolaryngol Head Neck Surg 2007;15:274-80.

17. Jackson J, Fiddler M, Kapur N, et al. Number of bodily symptoms predicts outcome more accurately than health anxiety in patients attending neurology, cardiology, and gastroenterology clinics. J Psychosom Res 2006;60:357-63.

18. Petrie KJ, Weinman J. Patients' perceptions of their illness: the dynamo of volition in health care. Curr Dir Psychol Sci 2012;21: $60-5$.

19. Horne R, Weinman J. Self-regulation and self-management in asthma: exploring the role of illness perceptions and treatment beliefs in explaining non-adherence to preventer medication. Psychol Health 2002;17:17-32.

20. Moss-Morris R, Wrapson W. Representational beliefs about functional somatic syndromes. In: Cameron LD, Leventhal H, eds. The self regulation of health and illness behaviour. London: Routledge, 2003:119-37.

21. Frostholm L, Oernboel E, Christensen KS, et al. Do illness perceptions predict health outcomes in primary care patients? A 2-year follow-up study. J Psychosom Res 2007;62:129-38.

22. Rief W, Broadbent $E$. Explaining medically unexplained symptoms-models and mechanisms. Clin Psychol Rev 2007;27:821-41.

23. Bailer J, Witthöft M, Rist F. Psychological predictors of short-and medium term outcome in individuals with idiopathic environmental intolerance (IEI) and individuals with somatoform disorders. $J$ Toxicol Environ Health Part A 2008;71:766-75.

24. Staudenmayer $\mathrm{H}$. Idiopathic environmental intolerances (IEI): myth and reality. Toxicol Lett 2001;120:333-42.

25. Jackson JL, Kroenke K. Managing somatization: medically unexplained should not mean medically ignored. J Gen Intern Med 2006;21:797-9.

26. Brown RJ. Psychological mechanisms of medically unexplained symptoms: an integrative conceptual model. Psychol Bull 2004;130:793-812. 
27. Deary V, Chalder T, Sharpe M. The cognitive behavioural model of medically unexplained symptoms: a theoretical and empirical review. Clin Psychol Rev 2007;27:781-97.

28. Witthöft M, Gerlach AL, Bailer J. Selective attention, memory bias, and symptom perception in idiopathic environmental intolerance and somatoform disorders. J Abnorm Psychol 2006;115:397-407.

29. Brosschot JF. Markers of chronic stress: prolonged physiological activation and (un) conscious perseverative cognition. Neurosci Biobehav Rev 2010;35:46-50.

30. Brosschot JF, Gerin W, Thayer JF. The perseverative cognition hypothesis: a review of worry, prolonged stress-related physiologica activation, and health. J Psychosom Res 2006;60:113-24.

31. Norbäck D. An update on sick building syndrome. Curr Opin Allergy Clin Immunol 2009;9:55-9.

32. Marmot AF, Eley J, Stafford M, et al. Building health: an epidemiological study of "sick building syndrome" in the Whitehall II study. Occup Environ Med 2006;63:283-9.

33. Allen LA, Woolfolk RL, Escobar JI, et al. Cognitive-behavioral therapy for somatization disorder: a randomized controlled trial. Arch Intern Med 2006;166:1512-18.

34. Escobar JI, Gara MA, Diaz-Martinez AM, et al. Effectiveness of a time-limited cognitive behavior therapy type intervention among primary care patients with medically unexplained symptoms. Ann Fam Med 2007:5:328-35.

35. Kleinstäuber M, Witthöft M, Hiller W. Efficacy of short-term psychotherapy for multiple medically unexplained physical symptoms: a meta-analysis. Clin Psychol Rev 2011;31:146-60.

36. Speckens AE, Van Hemert AM, Spinhoven P, et al. Cognitive behavioural therapy for medically unexplained physical symptoms: a randomised controlled trial. BMJ 1995;311:1328-32.

37. Tuomisto MT, Lappalainen R, Tuomisto T, et al. Sovellettu rentoutus hoitomenetelmänä psykiatriassa ja käyttäytymislääketieteessä [Applied relaxation in psychiatry and behavioral therapy]. Duodecim 1996:112:960-7.

38. Gockel M, Lindholm H, Tuomisto MT, et al. Työstressi, uupumus ja koettu työkyky: mittaaminen ja rentoutuksen vaikutus. Helsinki: Invalidisäätiö, 2004

39. Skovbjerg S, Hauge C, Rasmussen A, et al. Mindfulness-based cognitive therapy to treat multiple chemical sensitivities: a randomized pilot trial. Scand J Pychol 2012;53:233-8.

40. Sovijärvi AR, Malmberg LP, Reinikainen K, et al. A rapid dosimetric method with controlled tidal breathing for histamine challenge. Repeatability and distribution of bronchial reactivity in a clinical material. Chest 1993;104:164-70.

41. Quanjer PH, Lebowitz MD, Gregg I, et al. Peak expiratory flow: conclusions and recommendations of a Working Party of the European Respiratory Society. Eur Respir J Supp/ 1997;24:2S-8S.

42. Woolfolk RL, Allen LA. Treating somatization: a cognitive-behavioral approach. A Division of Guilford Publications, Inc. New York: The Guilford Press, 2007.

43. Waltz J, Addis ME, Koerner K, et al. Testing the integrity of a psychotherapy protocol: assessment of adherence and competence. J Consult Clin Psychol 1993:61:620-30.

44. Ost LG. Applied relaxation: description of a coping technique and review of controlled studies. Behav Res Ther 1987;25:397-409.

45. Sintonen $\mathrm{H}$. The $15 \mathrm{D}$ instrument of health-related quality of life: properties and applications. Ann Med 2001;33:328-36.

46. Sintonen $\mathrm{H}$. The 15-d measure of health related quality of life: Reliability, validity and sensitivity of its health state descriptive system. Working Paper 41. Melbourne: National Centre for Health Program Evaluation, 1994

47. Tuomi K, IImarinen J, Jahkola A, et al. Work ability index. Helsinki: Finnish Institute of Occupational Health, 1998.

48. Karasek R, Theorell T. Healthy work: stress, productivity, and the reconstruction of working life. Basic books, 1992.

49. Karasek R, Brisson C, Kawakami N, et al. The Job Content Questionnaire (JCQ): an instrument for internationally comparative assessments of psychosocial job characteristics. J Occup Health Psychol 1998;3:322-55.

50. Sluiter JK, van der Beek AJ, Frings-Dresen MH. The influence of work characteristics on the need for recovery and experienced health: a study on coach drivers. Ergonomics 1999;42:573-83.

51. Spitzer RL, Kroenke K, Williams JB, et al. A brief measure for assessing generalized anxiety disorder: the GAD-7. Arch Intern Med 2006;166:1092-7.

52. Morin C M. Insomnia: psychological assessment and management. New York: Guilford Press, 1993.

53. Järnefelt $\mathrm{H}$, Hublin $\mathrm{C}$. Työikäisten unettomuuden hoito. Tammerprint Oy, Tampere: Finnish Institute of Occupational Health, 2012.

54. Derogatis LR, Lipman RS, Covi L. SCL-90: an outpatient psychiatric rating scale-preliminary report. Psychopharmacol Bull 1973;9:13-28.
55. Derogatis LR. Symptom Checklist-90-Revised, in Handbook of psychiatric measures. Washington DC: American Psychiatric Association, 2000:81-4.

56. Holi M. Assessment of psychiatric symptoms using the SCL-90 [PhD dissertation in Faculty of Medicine, Department of Psychiatry] Helsinki: University of Helsinki, 2003.

57. Kroenke K, Spitzer RL, Williams JB. The PHQ-9: validity of a brief depression severity measure. J Gen Intern Med 2001;16:606-13.

58. Kaila E, Väisänen A, Leino T, et al. ToMaHoK-Toimiva masennuksen hoitokäytäntö työterveyshuollossa. Painojussit Oy, Kerava: Finnish Institute of Occupational Health, 2012.

59. Mccurry SM, Hayes SC, Strosahl K, et al. Measuring experientia avoidance: a preliminary test of a working model. Psychol Rec 2004;54:553-78.

60. Bond FW, Hayes SC, Baer RA, et al. Preliminary psychometric properties of the Acceptance and Action Questionnaire-II: a revised measure of psychological inflexibility and experiential avoidance. Behav Ther 2011;42:676-88.

61. Robbins JM, Kirmayer LJ. Transient and persistent hypochondriacal worry in primary care. Psychol Med 1996;26:575-89.

62. Laakso V, Niemi PM, Grönroos M, et al. The worried young adult as a primary care patient. Fam Pract 2005;22:406-11.

63. Meyer TJ, Miller ML, Metzger RL, et al. Development and validation of the Penn State Worry Questionnaire. Behav Res Ther 1990;28:487-95.

64. Nurmi JE, Salmela-Aro K, Haavisto T. The strategy and attribution questionnaire: psychometric properties. Eur J Psychol Assess 1995;11:108-21.

65. Horvath AO, Greenberg LS. Development and validation of the Working Alliance Inventory. J Couns Psychol 1989;36:223-33.

66. Knekt $\mathrm{P}$, Lindfors $\mathrm{O}$. A randomized trial of the effect of four forms of psychotherapy on depressive and anxiety disorders. Design, methods, and results on the effectiveness of short-term psychodynamic psychotherapy and solution-focused therapy during a one-year follow-up. Studies in social security and health 77. Helsinki, Finland: The Social Insurance Institution, 2004.

67. Seligman ME. The effectiveness of psychotherapy: the Consumer Reports study. Am Psychol 1995;50:965-74

68. Saunders JB, Aasland OG, Babor TF, et al. Development of the alcohol use disorders identification test (AUDIT). WHO collaborative project on early detection of persons with harmful alcohol consumption-II. Addiction 1993;88:791-804.

69. Nathan RA, Sorkness CA, Kosinski M, et al. Development of the asthma control test: a survey for assessing asthma control. J Allergy Clin Immunol 2004;113:59-65.

70. Miller CS, Prihoda TJ. The Environmental Exposure and Sensitivity Inventory (EESI): a standardized approach for measuring chemical intolerances for research and clinical applications. Toxicol Ind Health 1999;15:370-85.

71. Holmes $\mathrm{TH}$, Rahe $\mathrm{RH}$. The social readjustment rating scale. J Psychosom Res 1967;11:213-18.

72. Lönnqvist J-E, Verkasalo M, Leikas S. Viiden suuren persoonallisuusfaktorin 10,60 , ja 300 osion julkiset mittarit. Psykologia 2008;43:338-42.

73. Horowitz, L M, Alden L E, Wiggins J S, et al. IIP: inventory of interpersonal problems: manual. San Antonio, Texas: The Psychological Corporation, 2000

74. Antonovsky A. Unraveling the mystery of health: how people manage stress and stay well. San Francisco: Jossey-Bass, 1987.

75. Sintonen $\mathrm{H}$. Terveyteen liittyvän elämänlaadun mittaaminen [Measurement of health-related quality of life]. Suomen Lääkäril 2013:68:1261-7.

76. Partio T. Official Statistics of Finland (OSF): statistics of occupational health care 2013. Helsinki,. 2015. http://www.kela.fi/documents/ 10180/1630858/Kelan_tyoterveyshuoltotilasto_2013.pdf/ c9ae7415-4fa7-4a59-99bd-1df77d1eb375 (accessed Dec 2015).

77. WHO. WHO guidelines for indoor air quality: dampness and mould. Copenhagen: WHO Regional Office for Europe, 2009. http://www. euro.who.int/ data/assets/pdf file/0017/43325/E92645.pdf (accessed Dec 2015)

78. Yorke J, Fleming SL, Shuldham C. Psychological interventions for adults with asthma: a systematic review. Respir Med 2007:101:1-14.

79. Yorke J, Fleming SL, Shuldham CM. Psychological interventions for adults with asthma. Cochrane Database Syst Rev 2006;(1):CD002982.

80. Di Blasi Z, Harkness E, Ernst E, et al. Influence of context effects on health outcomes: a systematic review. Lancet 2001;357:757-62.

81. Greenberg RP, Constantino MJ, Bruce N. Are patient expectations still relevant for psychotherapy process and outcome? Clin Psychol Rev 2006;26:657-78.

82. Kirmayer LJ, Sartorius N. Cultural models and somatic syndromes. Psychosom Med 2007;69:832-40. 


\section{Correction}

Selinheimo S, Vuokko A, Sainio M, et al. Comparing cognitive-behavioural psychotherapy and psychoeducation for non-specific symptoms associated with indoor air: a randomised control trial protocol. BMJ Open 2016;6:e011003. doi:10.1136/bmjopen-2015-011003

Some Competing interests were missed out of the original publication. The full Competing interests sections should read:

Competing interests All authors have completed the ICMJE uniform disclosure at www.icmje.org/coi_disclosure.pdf and declare: Financial support for the submitted work from The Finnish Work Environment Fund (ref 113076) and the Social Insurance Institution of Finland (KELA) (ref 23/26/2014); KK works as a medical expert in the Varma Mutual Pension Insurance Company (part-time work), KK worked as a medical expert in an Employment Pension Appeal Court (TELK), 1.2.2010-31.12.2014 (parttime consultancy) (in accordance with the Act on the Employment Pension Appeal Court); AV works as a medical expert in The Social Insurance Institute of Finland (KELA), Southern Insurance District (part-time work) and in The OP Insurance Ltd (part-time work), AK is also a a substitute member of the medical expert group, Unemployment Security Appeal Board (TTLK) (in accordance with the unemployment security commission Act); MS works as a part-time medical advisor for The Finnish Patient Insurance Centre, which handles all personal injuries that occur in connection with healthcare activities (in accordance with the Patient Injuries Act). No other activities that could appear to have influenced the submitted work. None of these institutions profits financially or non-financially from studying and publishing the methods and results of this intervention study. Neither the authors' institutions nor the funders have any authority over trial activities or preparing of the manuscript.

Open Access This is an Open Access article distributed in accordance with the Creative Commons Attribution Non Commercial (CC BY-NC 4.0) license, which permits others to distribute, remix, adapt, build upon this work non-commercially, and license their derivative works on different terms, provided the original work is properly cited and the use is non-commercial. See: http://creativecommons.org/licenses/by-nc/4.0/

BMJ Open 2017;7. doi:10.1136/bmjopen-2015-011003corr1

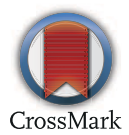

